\title{
Leaf rolling as indicator of water stress in Cistus incanus from different provenances
}

\author{
G. PUGLIELLI, L. GRATANI, and L. VARONE ${ }^{+}$ \\ Department of Environmental Biology, Sapienza University of Rome, P.le A. Moro 5, 00185 Rome, Italy
}

\begin{abstract}
Leaf movements such as leaf rolling affect plant physiological performance by reducing light capture. The relationship between leaf rolling and physiological traits under imposed water stress conditions was analyzed in two population of Cistus incanus. We tested the hypothesis that leaf rolling reflected physiological changes occurring during water stress irrespective of the different acclimation in order to cope with water stress. On the whole, our results confirmed our hypothesis since leaf rolling significantly reflected physiological activity changes. Moreover, leaf rolling might be involved in protecting the PSII complex under water stress during the progressive inhibition of photosynthetic metabolism. Thus, leaf rolling could be part of $C$. incanus adaptive strategy to cope with water stress by sustaining leaf turgor. As such, leaf rolling may be used as a morphological index to evaluate the progressive inhibition of photosynthesis irrespective of the different acclimation to cope with water stress.
\end{abstract}

Additional key words: apparent carboxylation efficiency; electron transport rate; photosynthesis; substomatal $\mathrm{CO}_{2}$ concentration.

\section{Introduction}

Leaf movements affect physiological performance because leaf orientation influences leaf energy balance (Gamon and Pearcy 1989) and has a role in adaptive responses to stress factors (Habermann et al. 2011, Kadioglu et al. 2012). Paraheliotropism, for example, is an efficient strategy to cope with high irradiance and high temperature and to avoid leaf photoinhibition under such stress conditions (Arena et al. 2008). Among leaf movements, leaf rolling is an hydronastic mechanism particularly involved in plant responses to water stress (Kadioglu et al. 2012). Although leaf rolling is used as a criterion to evaluate plant tolerance to water stress (Chunthong et al. 2017), its physiological role is not completely clarified. Several studies (Heckathorn and De Lucia, 1991, Kadioglu and Terzi 2007, Nar et al. 2009, Kadioglu et al. 2012) agree with considering that, under water stress conditions, stomatal conductance is the target of leaf rolling and affects as consequence also photosynthesis. Nevertheless, how leaf rolling affects stomatal conductance is still under debate. O'Toole and Cruz (1980) compared abaxial and adaxial leaf surface of two rice cultivars subjected to water stress and found that adaxial leaf surface had a lower stomatal resistance (i.e. a higher stomatal conductance, $g_{\mathrm{s}}$ ). In this case, the upper leaf surface rolling inside, due to leaf turgor decline, created a more favorable microenvironment (i.e. lower incident solar radiation and evaporative demand). Thus, stomata of the upper leaf surface had a lower responsiveness to negative leaf water potential and consequently a lower resistance (O'Toole and Cruz 1980). On the contrary, Abd Allah (2009) highlighted that leaf rolling reduces leaf surface exposed to sun light causing stomata closure and limiting $\mathrm{CO}_{2}$ uptake. Probably, the difficulty to clarify the effect arises from the several factors involved including stomatal distribution, as well as the degree and pattern of stomatal opening at low leaf water potential (Heckathorn and DeLucia 1991).

In Mediterranean ecosystems, the distribution of the dominant growth forms and habitus is related to water availability. According to a gradient of increasing aridity, there is a decrease in the transpiring surfaces up to the complete lack of leaves in drought-deciduous shrubs, associated with drought-evading annual species (De Micco and Aronne 2009). An intermediate form between evergreen and drought-deciduous species is represented by semideciduous species. Unlike drought-deciduous plants, in semideciduous species, the decrease in transpiring surfaces during the drought period is not complete.

$\overline{\text { Received }} 15$ December 2017, accepted 18 June 2018.

${ }^{+}$Corresponding author; e-mail: laura.varone@uniroma1.it

Abbreviations: $C_{\mathrm{a}}-\mathrm{CO}_{2}$ concentration in the leaf chamber; $C_{\mathrm{e}}-$ apparent carboxylation efficiency; $C_{\mathrm{i}}-$ intercellular $\mathrm{CO}_{2}$ concentration; Chl - chlorophyll; CP - saplings from Castelporziano; D1 - experimental day 1; D2 - experimental day 2; D3- experimental day 3; $\mathrm{DM}$ - leaf dry mass; $E$ - transpiration rate; ETR - electron transport rate; $\mathrm{F}_{\mathrm{m}}$ - maximal fluorescence yield of the dark-adapted state; $\mathrm{F}_{\mathrm{m}}{ }^{\prime}$ - maximal fluorescence yield of the light-adapted state; $\mathrm{F}_{\mathrm{s}}$ - steady-state fluorescence yield; FM - leaf fresh mass; $g_{\mathrm{s}}-$ stomatal conductance; LC - saplings from Monti Lucretili; $L_{\mathrm{n}}$ - the natural distance of the leaf blade margins; $L_{\mathrm{w}}-$ maximum leaf blade width; LRI - leaf rolling index; $P_{\text {Nsat }}$ - light-saturated net photosynthesis; RWC - relative water content; $\mathrm{T}_{1}-$ leaf temperature; $\mathrm{T}_{\text {mean }}-$ mean air temperature; $T_{\max }-$ mean maximum air temperature; $T_{\min }$ - mean minimum air temperature; $\Phi_{\text {PSII }}-$ actual quantum efficiency of of the PSII; $\Psi_{\text {leaf }}-$ leaf water potential. 
Among the semideciduous species, Cistus incanus L. is a typical Mediterranean shrub species distributed along the coastal belt of the Central-Eastern Mediterranean, Northern Africa, and Western Asia, extending from sea level to $800 \mathrm{~m}$ a.s.l. (Pignatti 1982). In this species, the efficient photosynthetic and photochemistry regulation has a fundamental adaptive role under different climatic conditions, allowing to optimize the carbon gain (De Micco et al. 2011, Vitale et al. 2014). In addition to physiological strategy, seasonal leaf dimorphism (i.e. displaying different leaf cohorts during a year) has been reported to be also an adaptive strategy to the seasonal climatic changes occurring in Mediterranean habitats (Christodoulakis et al. 1990, Kyparissis et al. 1997, Aronne and De Micco 2001). In fact, to cope with drought stress, $C$. incanus develops twigs with short internodes (brachyblasts) characterized by small xeromorphic leaves in summer, and twigs with longer internodes (dolichoblasts) with larger mesomorphic leaves in winter (De Micco and Aronne 2009). Seasonal dimorphic Cistus sp. are known to avoid drought-induced damages at a physiological level by leaf movements such as variation in leaf angle and leaf rolling (Werner et al. 1999, 2001, Flexas et al. 2014, Puglielli et al. 2017).

The aim of this research was to analyze the relationship between leaf rolling and physiological variables in C. incanus saplings subjected to induced water stress. Our working hypothesis was that under water-stress conditions, leaf rolling reflected physiological changes irrespective of the plant capacity acclimation. To test this hypothesis, we considered two populations of $C$. incanus growing at the altitudinal limits of its distribution area. In particular, the population growing at the highest altitude (i.e. $750 \mathrm{~m}$ a.s.1., mountain habitat) faces lower chilling temperatures during winter and a higher amount of precipitation during the year associated with a reduced extent of summer drought. On the contrary, the population growing at lower altitude (i.e. $0 \mathrm{~m}$ a.s.1., coastal habitat) faces a reduced amount of precipitation during the year associated with a prolonged summer drought. As the populations were subjected to different selective pressures, we expected a different acclimation to water stress. In particular, the population from mountain should show a lower acclimation capacity to water stress than that of the coastal population. Thus, if our working hypothesis was verified, leaf rolling should reflect the same physiological changes in both the populations.

\section{Materials and methods}

Study site and plant material: The study was carried out in July 2014 at the experimental garden of Sapienza University of Rome ( $41^{\circ} 54^{\prime} \mathrm{N}, 12^{\circ} 31^{\prime} \mathrm{E}$; $41 \mathrm{~m}$ a.s.1.). Threeyear old saplings of $C$. incanus grown from seeds collected in June 2012 in the Mediterranean maquis developing along the Latium coast near Rome (Castelporziano, $41^{\circ} 45^{\prime} \mathrm{N}, 12^{\circ} 26^{\prime} \mathrm{E}, 0 \mathrm{~m}$ a.s.1.) and at the Natural Park of Monti Lucretili $\left(42^{\circ} 33^{\prime} \mathrm{N}, 12^{\circ} 54^{\prime} \mathrm{E}, 750 \mathrm{~m}\right.$ a.s.1.) were considered. Saplings (twenty saplings per provenance) were cultivated in plastic pots $(32 \mathrm{~cm}$ in diameter and $29 \mathrm{~cm}$ in depth) containing silt (5-8\%), clay (16-39\%), and sand (56-75\%) (pH 7.2-7.5) and grown inside a growth chamber under constant PPFD of $600 \mu \mathrm{mol}$ (photon) $\mathrm{m}^{-2} \mathrm{~s}^{-1}$ $(12 \mathrm{~h})$, at $25 / 20{ }^{\circ} \mathrm{C}$ light/dark average temperature, and $50 / 40 \%$ relative air humidity.

The provenance sites are characterized by a Mediterranean climate (Fig. 1). In particular, at Castelporziano, the mean minimum air temperature $\left(\mathrm{T}_{\min }\right)$ of the coldest months (January and February) is $4.8 \pm 2.3^{\circ} \mathrm{C}$, the mean maximum air temperature $\left(\mathrm{T}_{\max }\right)$ of the hottest months (July and August) is $30.5 \pm 1.8^{\circ} \mathrm{C}$, and the yearly mean air temperature $\left(\mathrm{T}_{\text {mean }}\right)$ is $16.4 \pm 6.1^{\circ} \mathrm{C}$. The dry period is from mid-May to August (48.3 mm of total rainfall in this period). Total annual rainfall equals $824 \mathrm{~mm}$ with the greatest part occurring in autumn and in winter (data from Meteorological Station of Roma Capocotta, SIARL, Arsial, for the period 2004-2013).

At the Natural Park of Monti Lucretili, the $\mathrm{T}_{\min }$ of the coldest months (January and February) is $0.5 \pm 1.6^{\circ} \mathrm{C}$, the $\mathrm{T}_{\max }$ of the hottest months (July and August) is $32.7 \pm$ $1.6^{\circ} \mathrm{C}$, and the yearly $\mathrm{T}_{\text {mean }}$ is $14.3 \pm 6.7^{\circ} \mathrm{C}$. The dry period is from mid-June to August (63.9 mm of total rainfall in this period). Total annual rainfall equals $1077 \mathrm{~mm}$ with the greatest part occurring in autumn and in winter (data from Meteorological Station of Palombara Sabina, SIARL, Arsial, for the period 2004-2013).

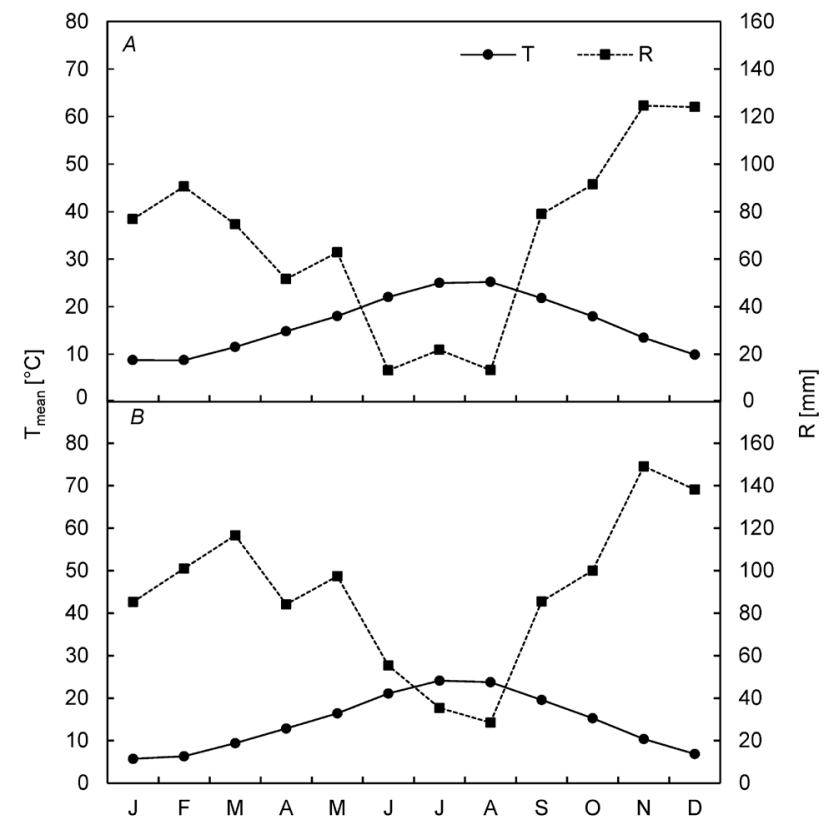

Fig. 1. Bagnouls-Gaussen's diagram (time series 2004-2013) showing monthly mean air temperature $\left(\mathrm{T}_{\text {Mean }}\right)$ and monthly total rainfall $(\mathrm{R})$ for $A$ : Castelporziano $\left(41^{\circ} 45^{\prime} \mathrm{N}, 12^{\circ} 26^{\prime} \mathrm{E}, 0 \mathrm{~m}\right.$ a.s.l.) and for $B$ : The Natural Park of Monti Lucretili $\left(42^{\circ} 33^{\prime} \mathrm{N}\right.$, $12^{\circ} 54^{\prime} \mathrm{E}, 750 \mathrm{~m}$ a.s.1.).

Experimental procedure: Until the onset of the experiment (on 5 July), twenty saplings from Castelporziano and from Monti Lucretili (CP and LC saplings, respectively) were watered regularly to a field capacity. Gas exchange, leaf water status, chlorophyll (Chl) fluorescence, and leaf rolling index measurements for the control saplings were performed on the first day of the experiment when all the 
saplings were well watered. Thereafter, the water stress was imposed by withholding water from ten $\mathrm{CP}$ and ten LC saplings, randomly arranged (stressed saplings, CPs and LCs, for Castelporziano and Monti Lucretili, respectively). In each sampling day, measurements were carried out on six randomly selected saplings per provenance.

The remaining ten saplings per provenance were kept under daily irrigation and measured in order to verify that the considered parameters maintained constant values through the experiment (control saplings, CPc and LCc for Castelporziano and Monti Lucretili, respectively). The water stress experiment was stopped when $g_{\mathrm{s}}$ in CPs and LCs was below $0.05 \mathrm{~mol}\left(\mathrm{H}_{2} \mathrm{O}\right) \mathrm{m}^{-2} \mathrm{~s}^{-1}$ indicative of a severe water-stress conditions (Medrano et al. 2002). The whole experiment lasted four days. Thereafter, the experimental days are indicated as D1 (first experimental day), D2 (two days after the beginning of the experiment), and D3 (four days after the beginning of the experiment).

Gas exchange: During the experiment, light-saturated net photosynthetic rate $\left(P_{\text {Nsat }}\right)$, stomatal conductance $\left(g_{\mathrm{s}}\right)$, leaf transpiration $(E)$, and substomatal $\mathrm{CO}_{2}$ concentration $\left(C_{\mathrm{i}}\right)$ were measured with an open infrared gas analyzer system $(L C p r o+, A D C, \mathrm{UK})$, equipped with a leaf chamber $(P L C$, $A D C, \mathrm{UK})$.

Measurements were carried out while the natural inclination of the leaves was maintained. Between each measurement, the IRGA was calibrated for $\mathrm{CO}_{2}$ and water vapor following the instructions of the manufacturers.

Six measurements on young fully expanded sun leaves per each selected control and stressed sapling were carried out every two days in the morning (11.00-12.30 h) at saturating PPFD $\left[1,500 \mu \mathrm{mol}\left(\right.\right.$ photon) $\left.\mathrm{m}^{-2} \mathrm{~s}^{-1}\right]$ provided by the light source (LCpro+ lamp unit). Before each measurement, the leaves were acclimated to saturated light conditions ( $\mathrm{ca} .15-20 \mathrm{~min}) . \mathrm{CO}_{2}$ concentration in the leaf chamber $\left(C_{\mathrm{a}}\right)$ was set at $400 \mu \mathrm{mol}\left(\mathrm{CO}_{2}\right) \mathrm{mol}^{-1}$ (air), and relative air humidity of the incoming air ranged between 40 and $60 \%$. Leaf temperature $\left(\mathrm{T}_{1}\right)$ was set at $25^{\circ} \mathrm{C}$ and varied by $1 \%$ during measurements. Apparent carboxylation efficiency $\left(C_{\mathrm{e}}\right)$ was also determined by the ratio between $P_{\max }$ and $C_{\mathrm{i}}$ (Flexas et al. 2001).

Chlorophyll (Chl) fluorescence: Measurements of Chl fluorescence were carried out on the same leaves of gasexchange measurements, using a portable modulated fluorometer (OS5p, Opti-Sciences, USA). Chl fluorescence measurements were carried out at saturating PPFD [i.e. 1,500 $\mu \mathrm{mol}$ (photon) $\mathrm{m}^{-2} \mathrm{~s}^{-1}$ ] ensuring a uniform light distribution on leaf surface while maintaining an inclination of the fluorometer pulse source at $45^{\circ}$.

The actual quantum efficiency of the PSII ( $\left.\Phi_{\text {PSII }}\right)$ was calculated according to Genty et al. (1989) as: $\Phi_{\text {PSII }}=$ $\left(F_{m}{ }^{\prime}-F_{s}\right) / F_{m}$ ', where $F_{m}$ ' was the maximum fluorescence obtained with a saturating pulse [ca. PPFD of 8,000 $\mu \mathrm{mol}\left(\right.$ photon) $\left.\mathrm{m}^{-2} \mathrm{~s}^{-1}\right]$ and $\mathrm{F}_{\mathrm{s}}$ was the steady-state fluorescence of illuminated leaves $\left[1,500 \mu \mathrm{mol}\left(\right.\right.$ photon) $\left.\mathrm{m}^{-2} \mathrm{~s}^{-1}\right]$.

The rate of electron transport rate [ETR, $\mu \mathrm{mol}\left(\mathrm{e}^{-}\right)$ $\mathrm{m}^{-2} \mathrm{~s}^{-1}$ ] was calculated, according to Krall and Edwards
$(1992)$ as: $\mathrm{ETR}=\left(\Phi_{\mathrm{PSII}}\right) \times \mathrm{PPFD} \times 0.5 \times 0.84$

Leaf water status: Leaf water potential $\left(\Psi_{\text {leaf }}\right)$ was measured in control and stressed plants by a pressure bomb (SKPM 1400, Sky Instruments, Powys, UK). Samples were enclosed in a bag previously saturated with $\mathrm{CO}_{2}$ and water vapor in order to avoid water losses from stomata. Measurements were carried out in each sampling occasion on four leaves per each of the considered sapling after gas-exchange measurements. In addition, relative water content (RWC) was measured as: RWC = $[(\mathrm{FM}-\mathrm{DM}) /(\mathrm{TM}-\mathrm{DM})] \times 100$, where $\mathrm{FM}$ was the leaf fresh mass, DM was the leaf dry mass after drying at $80^{\circ} \mathrm{C}$ until constant mass was reached, and TM was the leaf mass after rehydration until saturation for $48 \mathrm{~h}$ at $5^{\circ} \mathrm{C}$ in the darkness.

Leaf rolling index (LRI) was calculated on the same leaves used for gas-exchange measurements according to Li et al. (2010) as: $\operatorname{LRI}=\left[\left(L_{\mathrm{w}}-L_{\mathrm{n}}\right) / L_{\mathrm{w}}\right] \times 100$, where $L_{\mathrm{w}}$ was the maximum leaf blade width and $L_{\mathrm{n}}$ the natural distance of the leaf blade margins (Fig. 2). For LRI measurements, $L_{\mathrm{w}}$ was measured only at D1 in order to avoid any confounding effect of leaf manipulation on gas-exchange and $\mathrm{Chl}$ fluorescence measurements.

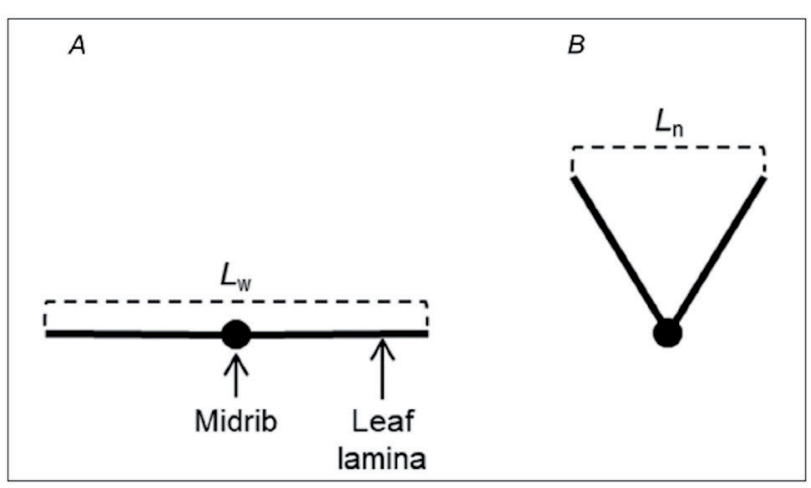

Fig. 2. Schematic representation of the parameters used to calculate leaf rolling index (LRI, \%) in Cistus incanus leaves. $A$ : Maximum leaf blade width $(L \mathrm{w}), B$ : Natural distance of the leaf blade margins $(L n)$. LRI was calculated as: LRI = $[(L \mathrm{w}-L \mathrm{n}) / L \mathrm{w}] \times 100$.

Statistical analysis: One-way analysis of variance (ANOVA) was performed to evaluate the differences between CPs and LCs and between stressed and control saplings at $p \leq 0.05$. Multiple comparisons were analyzed by a Tukey's test. Regression analysis was used to explore the relationships among the considered variables. Relationships were considered significant at $p \leq 0.01$. Kolmogorov-Smirnov's and Levene's tests were used to verify the assumptions of normality and homogeneity of variances, respectively. All data are shown as mean \pm SD. All the statistic tests were performed by a statistical software package (Statistica.8, Stasoft, USA). 


\section{Results}

Gas exchange: During the experiment, the highest $P_{\text {Nsat }}$ values were measured at D1 for both $\mathrm{CPs}$ and $\mathrm{LCs}$ $\left[18.6 \pm 2.6\right.$ and $10.5 \pm 2.6 \mu \mathrm{mol}\left(\mathrm{CO}_{2}\right) \mathrm{m}^{-2} \mathrm{~s}^{-1}$, respectively] (Fig. 3). $P_{\text {Nsat }}$ significantly decreased by $32 \%$ and $83 \%$ at D2 and D3, respectively in CPs, and by $23 \%$ and $88 \%$ , respectively, in LCs (Fig. $3 A$ ). $g_{\mathrm{s}}$ showed the same $P_{\text {Nsat }}$ trend significantly dropping below $0.05 \mathrm{~mol}\left(\mathrm{H}_{2} \mathrm{O}\right) \mathrm{m}^{-2} \mathrm{~s}^{-1}$ at D3 for both CPs and LCs (Fig. $3 B$ ).

In CPs saplings, $C_{\mathrm{i}}$ was $260 \pm 9.8 \mathrm{ppm}$ at D1, decreasing by $6 \%$ at $\mathrm{D} 2$, and increasing by $9 \%$ at $\mathrm{D} 3$ compared to D1. In LCs, $C_{\mathrm{i}}$ increased during the experiment by $11 \%$ and $41 \%$ at D2 and D3, respectively, compared to D1 (224 $\pm 22 \mathrm{ppm})$

$C_{\mathrm{e}}$ did not significantly vary between D1 and D2 in CPs $(0.04 \pm 0.01)$, while it significantly decreased by $75 \%$ at D3. In LCs, $C_{\mathrm{e}}$ significantly decreased by $50 \%$ and $92 \%$ at D2 and D3, respectively, compared to D1 $(0.04 \pm 0.01)$ (Fig. 3D).

The control plants did not show any significant variation in gas-exchange parameters during the experiment both in CPs and LCs.

Chl fluorescence: In particular, in CPs ETR showed a decreasing trend (by $14 \%$ and $30 \%$ ) at D2 and D3, respectively, compared to D1 $\left[221.9 \pm 20.2 \mu \mathrm{mol}\left(\mathrm{e}^{-}\right)\right.$ $\mathrm{m}^{-2} \mathrm{~s}^{-1}$ ] (Fig. 4A). $\Phi_{\text {PSII }}$ showed the same ETR trend with the highest value at D1 $(0.38 \pm 0.05)$ significantly decreasing by $8 \%$ and $37 \%$ In LCs saplings ETR and $\Phi_{\text {PSII }}$ through the experiment did not vary significantly between the experimental days (Fig. 4A,B).
Leaf water status: CPs and LCs showed a significant decrease (by $113 \%$ and $133 \%$, respectively) in $\Psi_{\text {leaf }}$ compared to $\mathrm{D} 1(-1.50 \pm 0.2$ and $-1.50 \pm 0.02 \mathrm{MPa}$ for $\mathrm{CPc}$ and $\mathrm{LCc}$, respectively) (Table 1). RWC was $100 \%$ at D1 in both control and stressed saplings significantly decreasing by $75 \%$ in both CPs and LCs at D3. Control plants did not show any significant variation of RWC and $\Psi_{\text {leaf }}$ during the experiment.

Leaf rolling index: At D1 both CPs and LCs did not show any symptom of rolling (Table 2). At D2, LRI did not significantly increase in CPs and in LCs. LRI significantly increased by $7 \%$ and $28 \%$ in CPs and LCs, respectively, at D3. Control saplings did not show any symptom of rolling during the experiment (Table 2).

The relationships between LRI and the considered physiological variables are shown in Fig. 5. LRI showed a linear relationship $(p \leq 0.01)$ with $C_{\mathrm{i}}\left(R^{2}=0.62\right.$ and $R^{2}=0.73$, for CPs and LCs, respectively) and $g_{\mathrm{s}}\left(R^{2}=-0.62\right.$ and $R^{2}=-0.73$, for CPs and LCs, respectively). LRI was also significantly $(p \leq 0.01)$ related with $C_{\mathrm{e}}$ in both CPs and LCs $\left(R^{2}=-0.76\right.$ and $R^{2}=-0.81$, respectively) while it is significantly correlated with ETR only in CPs $\left(R^{2}=-0.41\right)$.

\section{Discussion}

The results highlighted a different response of CPs and LCs to water stress, which reflects their different provenance. In fact, LCs saplings, which experienced a shorter period of drought in their natural environment in respect to $\mathrm{CP}$ saplings, were characterized by a higher sensitivity to water stress highlighted by a faster metabolic impairment.

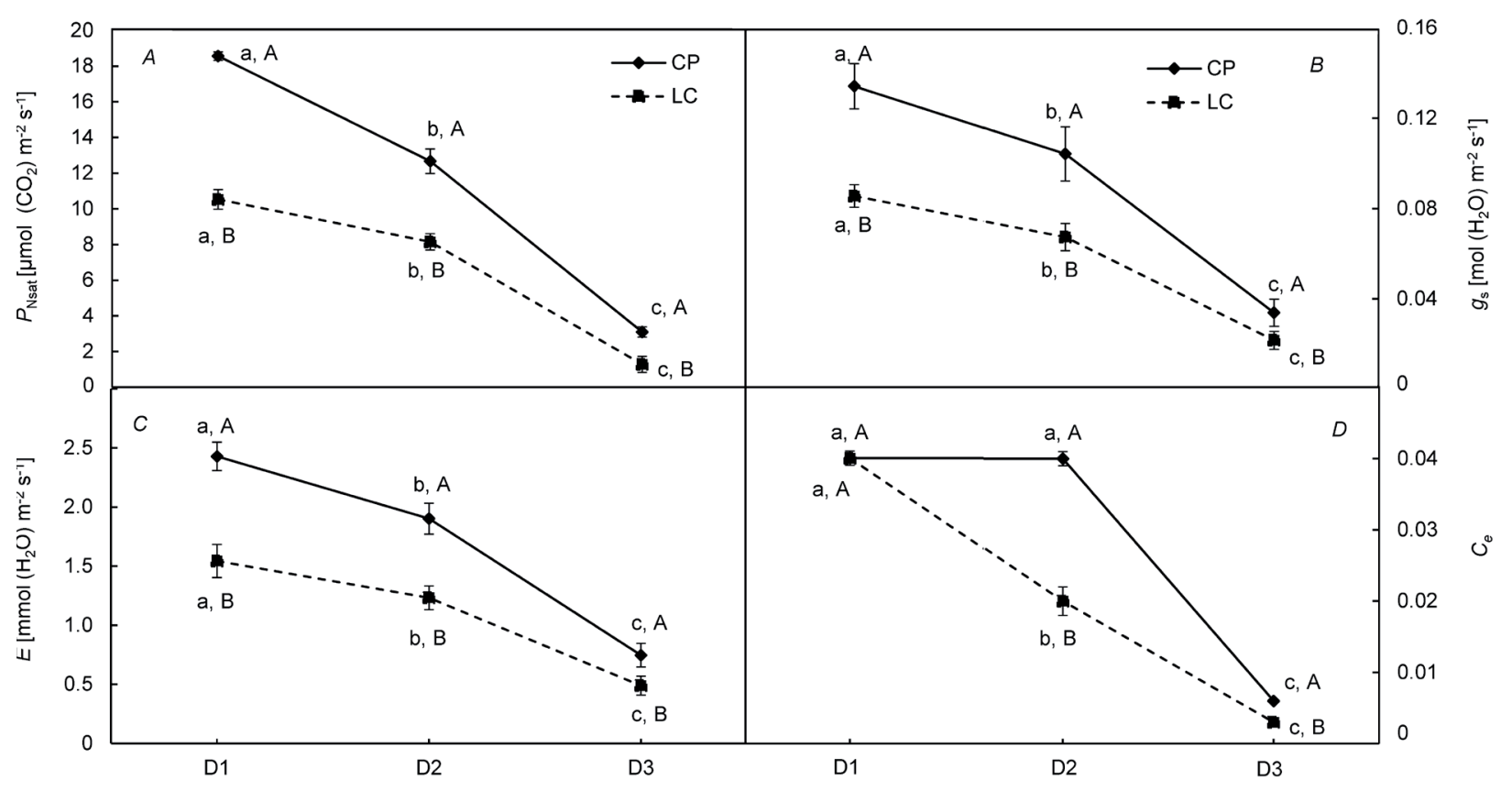

Fig. 3. Trends of $A$ : light-saturated net photosynthetic rate $\left(P_{\text {Nsat }}\right), B$ : stomatal conductance $\left(g_{\mathrm{s}}\right), C$ : leaf transpiration $(E)$, and $D$ : carboxylation efficiency $\left(C_{\mathrm{e}}\right)$ measured during the first experimental day (D1), two days after the beginning of the experiment (D2), and four days after the beginning of the experiment (D3) of stressed Cistus incanus saplings from Castelporziano (CPs, black line) and from the Natural Park of Monti Lucretili (LCs, gray line). Mean values $( \pm \mathrm{SE})$ are shown $(n=36)$. Lowercase letters show significant differences between experimental days, capital letters show significant differences between CPs and LCs saplings at $p \leq 0.05$. 


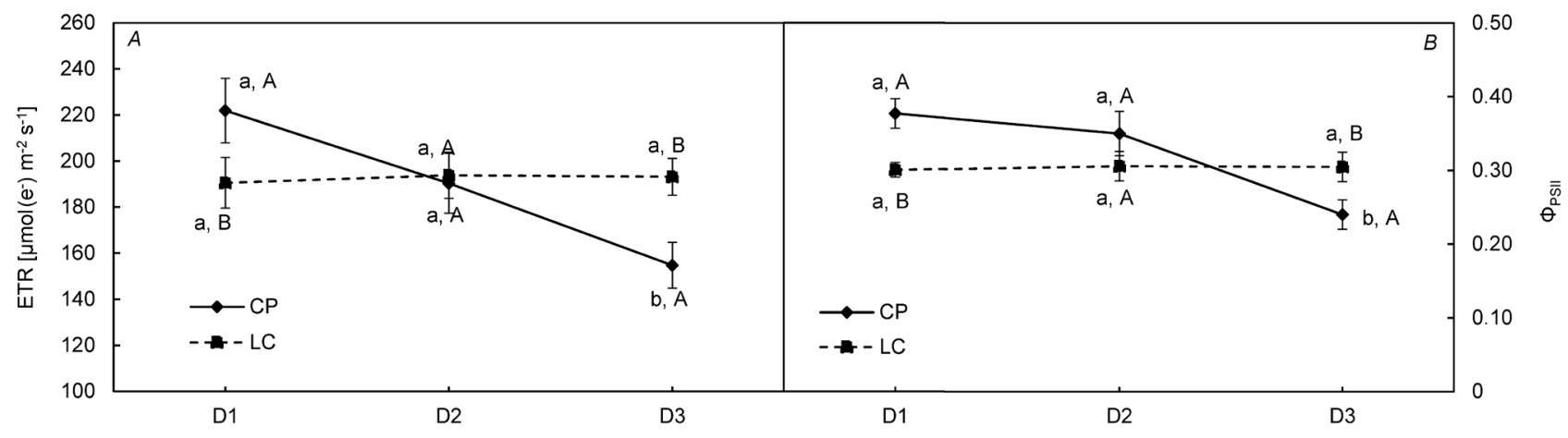

Fig. 4. Trends of: $A$ : rate of electron transport (ETR), and $B$ : the actual quantum efficiency of the photosystem II ( $\left.\Phi_{\text {PSII }}\right)$ measured during the first experimental day (D1), two days after the beginning of the experiment (D2), and four days after the beginning of the experiment (D3) of stressed Cistus incanus saplings from Castelporziano (CPs, black line) and from the Natural Park of Monti Lucretili (LCs, gray line). Mean values $( \pm \mathrm{SE})$ are shown $(n=36)$. Lowercase letters show significant differences between experimental days, capital letters show significant differences between CPs and LCs saplings at $p \leq 0.05$.

Table 1. Leaf water potential ( $\Psi_{\text {leaf }}$ ) and relative water content (RWC) measured during the first experimental day (D1), two days after the beginning of the experiment (D2), and four days after the beginning of the experiment (D3). CPs - stressed saplings of Cistus incanus from Castelporziano, CPc - control saplings of Cistus incanus from Castelporziano, LCs - stressed saplings of Cistus incanus from Natural Park of Monti Lucretili, LCc - control saplings of Cistus incanus from Natural Park of Monti Lucretili. Mean values ( \pm $\mathrm{SE})$ are shown $(n=24)$. Lowercase letters show significant differences between experimental days, capital letters show significant differences between control and stressed saplings at $p \leq 0.05$.

\begin{tabular}{|c|c|c|c|c|c|c|c|c|}
\hline & \multicolumn{4}{|l|}{$\Psi_{\text {leaf }}[\mathrm{MPa}]$} & \multicolumn{4}{|l|}{ RWC [\%] } \\
\hline & $\mathrm{CPs}$ & $\mathrm{CPc}$ & $\mathrm{LCs}$ & $\mathrm{LCc}$ & CPs & $\mathrm{CPc}$ & $\mathrm{LCs}$ & $\mathrm{LCc}$ \\
\hline$\overline{\mathrm{D} 1}$ & $-1.50 \pm 0.2^{\mathrm{a}, \mathrm{A}}$ & $-1.54 \pm 0.03^{\mathrm{a}, \mathrm{A}}$ & $-1.50 \pm 0.02^{\mathrm{a}, \mathrm{A}}$ & $-1.48 \pm 0.01^{\mathrm{a}, \mathrm{A}}$ & $98 \pm 0.02^{\mathrm{a}, \mathrm{A}}$ & $100 \pm 0.01^{\mathrm{a}, \mathrm{A}}$ & $99 \pm 0.02^{\mathrm{a}, \mathrm{A}}$ & $99 \pm 0.008^{\mathrm{a}, \mathrm{A}}$ \\
\hline D2 & $-1.90 \pm 0.1^{\mathrm{b}, \mathrm{A}}$ & $-1.53 \pm 0.03^{\mathrm{a}, \mathrm{B}}$ & $-2.10 \pm 0.01^{\mathrm{b}, \mathrm{A}}$ & $-1.52 \pm 0.01^{\mathrm{a}, \mathrm{B}}$ & $84 \pm 0.01^{\mathrm{b}, \mathrm{A}}$ & $98 \pm 0.02^{\mathrm{a}, \mathrm{B}}$ & $82 \pm 0.03^{\mathrm{b}, \mathrm{A}}$ & $99 \pm 0.002^{\mathrm{a}, \mathrm{B}}$ \\
\hline D3 & $-3.20 \pm 0.03^{\mathrm{c}, \mathrm{A}}$ & $-1.52 \pm 0.02^{\mathrm{a}, \mathrm{B}}$ & $-3.50 \pm 0.07^{\mathrm{c}, \mathrm{A}}$ & $-1.54 \pm 0.02^{\mathrm{a}, \mathrm{B}}$ & $75 \pm 0.07^{\mathrm{c}, \mathrm{A}}$ & $98 \pm 0.02^{\mathrm{a}, \mathrm{B}}$ & $76 \pm 0.06^{\mathrm{c}, \mathrm{A}}$ & $98 \pm 0.009^{\mathrm{a}, \mathrm{B}}$ \\
\hline
\end{tabular}

In particular, both CPs and LCs showed the lowest values of $\Psi_{\text {leaf }}(-3.2 \pm 0.03$ and $-3.5 \pm 0.05 \mathrm{MPa}$, respectively) at D3 reaching the RWC value of $75.5 \pm 0.7 \%$. When expressed as percentage of the control, $P_{\mathrm{Nsat}}, g_{\mathrm{s}}$, and $E$ trends were similar in CPs and LCs. Nevertheless, ETR and $C_{\mathrm{e}}$ were the parameters that showed the greatest differences between CPs and LCs.

According to Lawlor and Cornic (2002), the decrease in RWC increases $C_{\mathrm{i}}$. However, in CPs, $C_{\mathrm{i}}$ decreased at D2 $(6 \%)$ and increased by $9 \%$ at D3, compared to D1. In response to stomatal closure, $\mathrm{CO}_{2}$ inside the leaf initially declines, then it increases as drought becomes more severe (Lawlor 1995). The decrease in $C_{\mathrm{i}}$ at D2 for CPs plants suggests that stomatal limitations dominate under moderate water stress, irrespective of any metabolic impairment (Flexas and Medrano 2002). However, at a certain stage of water stress, $C_{\mathrm{i}}$ frequently increases highlighting the predominance of nonstomatal limitations of photosynthesis. Usually, the point, at which $C_{\mathrm{i}}$ starts to increase, occurs around $g_{s}$ values of $0.05 \mathrm{~mol}\left(\mathrm{H}_{2} \mathrm{O}\right)$ $\mathrm{m}^{-2} \mathrm{~s}^{-1}$ (Flexas and Medrano 2002). Accordingly, CPs showed the highest value of $C_{\mathrm{i}}$ at $\mathrm{D} 3$ when $g_{\mathrm{s}}$ was 0.03 $\operatorname{mol}\left(\mathrm{H}_{2} \mathrm{O}\right) \mathrm{m}^{-2} \mathrm{~s}^{-1}$. On the contrary, in LCs, $C_{\mathrm{i}}$ increased through the experiment suggesting the occurrence of nonstomatal limitations in D2 when $g_{\mathrm{s}}$ was $0.07 \mathrm{~mol}\left(\mathrm{H}_{2} \mathrm{O}\right)$ $\mathrm{m}^{-2} \mathrm{~s}^{-1}$. The results were confirmed by the different $C_{\mathrm{e}}$ trend in CPs and LCs. In fact, in CPs, $C_{\mathrm{e}}$ significantly decreased only at D3, while in LCs it started declining from D2. A
RWC higher than $75 \%$ has not effect on photosynthetic metabolism (Lawlor and Cornic 2002). Nevertheless, the results of the experiment highlighted a faster progressive inhibition of metabolism in LCs, associated to a higher RWC (i.e. 80\%), than in CPs.

Water stress exposes plants to photoinhibition by reducing PSII efficiency and ETR (Cabrera 2002). This occurred in CPs but not in LCs. In particular, the ETR and $\Phi_{\text {PSII }}$ decreased in CPs at D2 may be interpreted as a downregulation mechanism at a lower photosynthesis (Biehler and Fock 1996, Cornic and Massacci 1996, Haupt-Herting and Fock 2000, 2002). Since the rate of electron transport at saturating photon flux is determined by sink capacity for electrons (such as photosynthesis at high RWC), a decreased sink capacity led to increase nonphotochemical energy dissipation (Lawlor and Cornic 2002). This may be justified by $\Phi_{\text {PSII }}$ reduction observed in CPs while the ETR decrease at D3 may be the result of nonstomatal limitations.

On the contrary, the lack of variation in ETR and $\Phi_{\text {PSII }}$ in LCs suggests that the redox system under water stress is in a reduced state due to continued electron transport and absence of sinks (Lawlor and Cornic 2002), as confirmed by the significant decrease in $C_{\mathrm{e}}$ through the experiment.

During the experiment, LCs showed leaf rolling (i.e. $\mathrm{LRI}=2 \pm 1 \%$ ) at D2 increasing to $28 \pm 14 \%$ at D3, while in CPs leaf rolling (LRI $=7 \pm 3 \%)$ appeared at D3. Since leaf rolling is a hydronastic mechanism, the delayed leaf rolling in CPs indicates the ability to sustain better turgor, despite 
Table 2. Leaf rolling index (LRI) measured during the first experimental day (D1), two days after the beginning of the experiment (D2), and four days after the beginning of the experiment (D3). CPs - stressed saplings of Cistus incanus from Castelporziano, $\mathrm{CPc}$ - control saplings of Cistus incanus from Castelporziano, LCs - stressed saplings of Cistus incanus from Natural Park of Monti Lucretili, LCc - control saplings of Cistus incanus from Natural Park of Monti Lucretili. Mean values $( \pm$ $\mathrm{SE})$ are shown $(n=24)$. Lowercase letters show significant differences between CPs and LCs saplings at $p \leq 0.05$.

\begin{tabular}{lllll}
\hline \multicolumn{5}{l}{ LRI $[\%]$} \\
& CPs & CPc & LCs & LCc \\
\hline D1 & 0 & 0 & 0 & 0 \\
D2 & 0 & 0 & $2 \pm 1$ & 0 \\
D3 & $7 \pm 3^{\mathrm{a}}$ & 0 & $28 \pm 14^{\mathrm{b}}$ & 0 \\
\hline
\end{tabular}

water stress, compared to LCs according to Kadioglu et al. (2012).

Moreover, LRI showed a significant linear relationship with $C_{\mathrm{i}}\left(R^{2}=0.62\right.$ and $R^{2}=0.73$, for CPs and LCs, respectively) and $g_{\mathrm{s}}\left(R^{2}=-0.62\right.$ and $R^{2}=-0.73$, for CPs and LCs, respectively), suggesting that LRI reflects the leaf physiological changing which occurred during water stress. LRI was also significantly related with $C_{\mathrm{e}}$ in both CPs and LCs $\left(R^{2}=-0.76\right.$ and $R^{2}=-0.81$, respectively) while it was significantly correlated with ETR only in CPs $\left(R^{2}=-0.41\right)$. The lack or the weakness of the relationship between LRI and ETR, associated to a strong negative relationship between LRI and $C_{\mathrm{e}}$ in both CPs and LCs, suggests that LRI is involved in protecting PSII under drought conditions (Nar et al. 2009) during the progressive inhibition of photosynthetic metabolism.

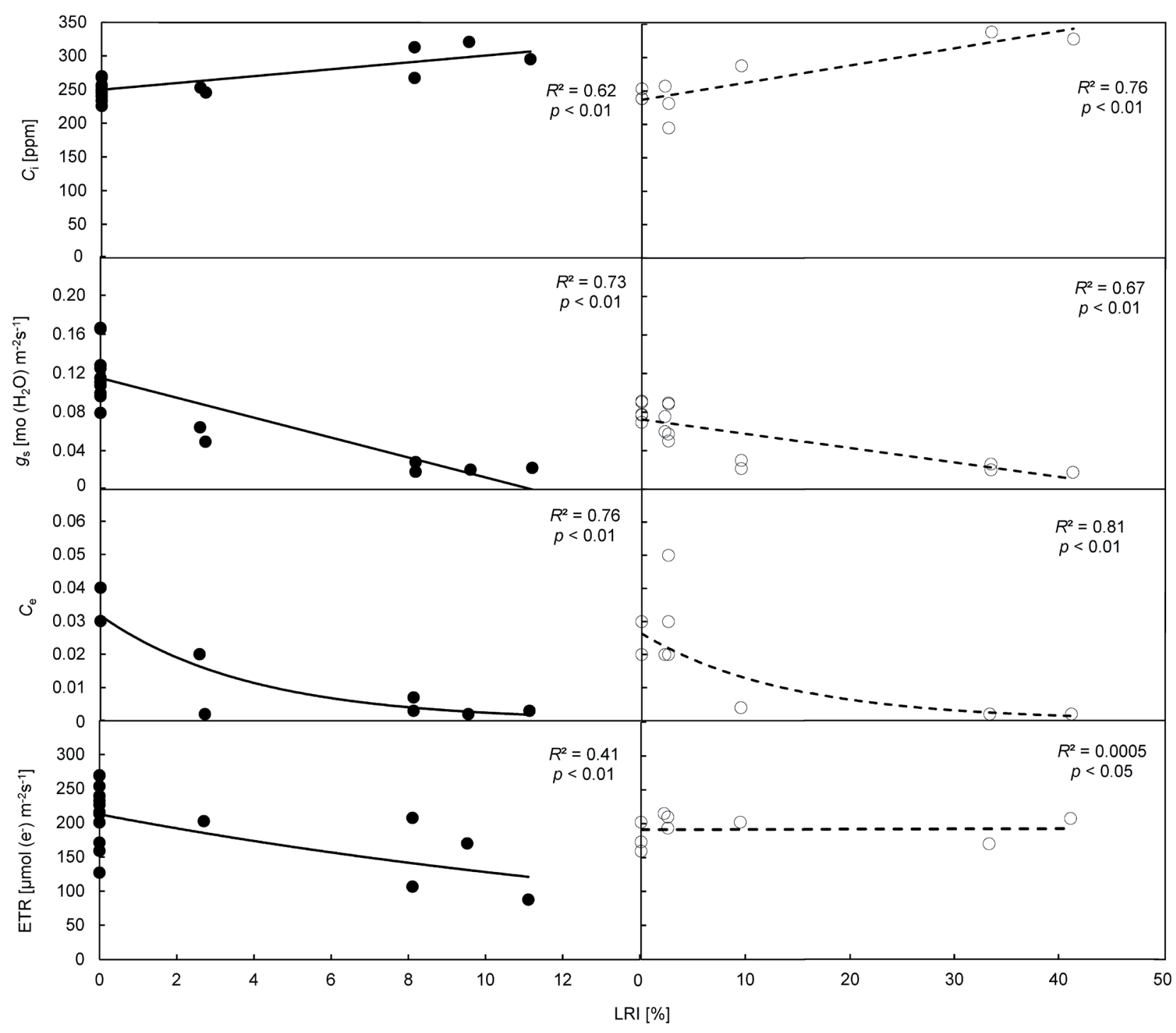

Fig. 5. Relationships between leaf rolling index (LRI) and substomatal $\mathrm{CO}_{2}$ concentration $\left(C_{\mathrm{i}}\right)$, stomatal conductance $\left(g_{\mathrm{s}}\right)$, carboxylation efficiency $\left(C_{\mathrm{e}}\right)$, and rate of electron transport (ETR) of stressed Cistus incanus saplings from Castelporziano (CPs, black dots, left column) and from the Natural Park of Monti Lucretili (LCs, white dots, right column). Daily mean values per sapling were used as experimental units $(n=18, p \leq 0.01)$. 
In conclusion, the results highlighted that leaf rolling is related to the physiological variables in both CPs and LCs despite their different response to water stress. Thus, leaf rolling in seasonal dimorphic Mediterranean species may be used as a morphological index not only to monitor the water status in the field but also to evaluate the progressive inhibition of photosynthetic metabolism irrespective to the different acclimation to cope with water stress.

\section{References}

Abd Allah A.A.: Genetic studies on leaf rolling and some root traits under drought conditions in rice (Oryza sativa L.). - Afr. J. Biotechnol. 8: 6241-6248, 2009.

Arena C., Vitale L., De Santo A.V.: Paraheliotropism in Robinia pseudoacacia L.: an efficient strategy to optimise photosynthetic performance under natural environmental conditions. - Plant Biol. 10: 194-201, 2008.

Aronne G., De Micco V.: Seasonal dimorphism in the Mediterranean Cistus incanus L. subsp. incanus. - Ann. Bot.London 87: 789-794, 2001.

Biehler K., Fock H.: Evidence for the contribution of the Mehlerperoxidase reaction in dissipating excess electrons in droughtstressed wheat. - Plant Physiol. 112: 265-272, 1996.

Cabrera H.M.: Ecophysiological responses of plants in ecosystems with Mediterranean-like climate and high mountain environments. - Rev. Chil. Hist. Nat. 75: 625-637, 2002.

Christodoulakis N.S., Tsimbani H., Fasseas C.: Leaf structural peculiarities in Sarcopoterium spinosum, a seasonally dimorphic subshrub. - Ann. Bot.-London 65: 291-296, 1990.

Chunthong K., Pitnjam K., Chakhonkaen S. et al.: Differential drought responses in F-box gene expression and grain yield between two rice groups with contrasting drought tolerance. J. Plant Growth Regul. 36: 970-982, 2017.

Cornic G., Massacci A.: Leaf photosynthesis under drought stress. - In: Baker N.R. (ed.): Photosynthesis and the Environment. Pp. 347-366. Kluwer Academic Publ., Dordrecht 1996.

De Micco V., Aronne G.: Seasonal dimorphism in wood anatomy of the Mediterranean Cistus incanus L. subsp. incanus. Trees-Struct. Funct. 23: 981-989, 2009.

De Micco V., Arena C., Vitale L. et al.: Anatomy and photochemical behaviour of Mediterranean Cistus incanus winter leaves under natural outdoor and warmer indoor conditions. - Botany 89: 677-688, 2011.

Flexas J., Medrano H.: Drought-inhibition of photosynthesis in C3 plants: stomatal and non-stomatal limitations revisited. Ann. Bot. (Lond.) 89: 183-189, 2002.

Flexas J., Gulías J., Jonasson S. et al.: Seasonal patterns and control of gas exchange in local populations of the Mediterranean evergreen shrub Pistacia lentiscus L. - Acta Oecol. 22: 33-43, 2001

Flexas J., Diaz-Espejo A., Gago J. et al:: Photosynthetic limitations in Mediterranean plants: A review. - Environ. Exp. Bot. 103: 12-23, 2014

Gamon J.A., Pearcy R.W.: Leaf movement, stress avoidance and photosynthesis in Vitis californica. - Oecologia 79: 475-481, 1989.

Genty B., Briantais J.M., Baker N.R.: The relationship between the quantum yield of photosynthetic electron transport and quenching of chlorophyll fluorescence. - Biochim. Biophys. Acta 990: 87-92, 1989.
Habermann G., Ellsworth P.F.V., Cazoto J.L. et al:: Leaf paraheliotropism in Styrax camporum confers increased light use efficiency and advantageous photosynthetic responses rather than photoprotection. - Environ. Exp. Bot. 71: 10-17, 2011.

Haupt-Herting S., Fock H.P.: Exchange of oxygen and its role in energy dissipation during drought stress in tomato plants. Physiol. Plantarum 110: 489-495, 2000.

Haupt-Herting S., Fock H.P.: Oxygen exchange in relation to carbon assimilation in drought stressed leaves during photosynthesis. - Ann. Bot.-London 89: 851-859, 2002.

Heckathorn S.A., De Lucia E.H.: Effect of leaf rolling on gas exchange and leaf temperature of Andropogon gerardii and Spartina pectinata. - Int. J. Plant Sci. 152: 263-268, 1991.

Kadioglu A., Terzi R.: A dehydration avoidance mechanism: leaf rolling. - Bot. Rev. 73: 290-302, 2007.

Kadioglu A., Terzi R., Saruhan N. et al.: Current advances in the investigation of leaf rolling caused by biotic and abiotic stress factors. - Plant Sci. 182: 42-48, 2012.

Krall J.P., Edwards G.E.: Relationship between photosystem II activity and $\mathrm{CO}_{2}$ fixation in leaves. - Physiol. Plantarum 86: 180-187, 1992.

Kyparissis A., Grammatikopoulos G., Manetas Y.: Leaf demography and photosynthesis as affected by the environment in the drought semi-deciduous Mediterranean shrub Phlomis fruticosa L. - Acta Oecol. 18: 543-555, 1997.

Lawlor D.W.: The effects of water deficit on photosynthesis. In: Smirnoff N. (ed.): Environment and Plant Metabolism. Pp. 129-160. Bios Sci. Publ., Oxford 1995.

Lawlor D.W., Cornic G.: Photosynthetic carbon assimilation and associated metabolism in relation to water deficits in higher plants. - Plant Cell Environ. 25: 275-294, 2002.

Li L., Shi Z.Y., Li L. et al.: Overexpression of ACL1 (abaxially curled leaf 1) increased bulliform cells and induced abaxial curling of leaf blades in Rice. - Mol. Plant. 3: 807-817, 2010.

Medrano H., Escalona J.M., Bota J. et al.: Regulation of photosynthesis of $\mathrm{C} 3$ plants in response to progressive drought: stomatal conductance as a reference parameter. - Ann. Bot.London 89: 895-905, 2002.

Nar H., Saglam A., Terzi R. et al.: Leaf rolling and photosystem II efficiency in Ctenanthe setosa exposed to drought stress. Photosynthetica 47: 429-436, 2009.

O'Toole J.C., Cruz R.T.: Response of leaf water potential, stomatal-resistance, and leaf rolling to water-stress. - Plant Physiol. 65: 428-432, 1980.

Pignatti S.: Flora d'Italia. Pp. 532. Edagricole, Bologna 1982.

Puglielli G., Redondo-Gómez S., Gratani L. et al.: Highlighting the differential role of leaf paraheliotropism in two Mediterranean Cistus species under drought stress and well-watered conditions. - J. Plant Physiol. 213: 199-208, 2017.

Vitale L., Magliulo V., Arena C.: Morphological and physiological modifications of Cistus salvifolius L. winter leaves in response to the rise in winter temperatures. - Plant Biosyst. 148: 10931101, 2014.

Werner C., Correia O., Beyschlag W.: Two different strategies of Mediterranean macchia plants to avoid photoinhibitory damage by excessive radiation levels during summer drought. - Acta Oecol. 20: 15-23, 1999.

Werner C., Ryel R.J., Correia O. et al.: Effects of photoinhibition on whole-plant carbon gain assessed with a photosynthesis model. - Plant Cell Environ. 24: 27-40, 2001.

(C) The authors. This is an open access article distributed under the terms of the Creative Commons BY-NC-ND Licence. 